\title{
Types of formation water and produced water in Danish oil- and gasfields: implications for enhanced oil recovery by injection of 'smart' water
}

\author{
Niels H. Schovsbo, Hanne D. Holmslykke, Claus Kjøller, Kathrine Hedegaard, Lars Kristensen \\ Erik Thomsen and Kim H. Esbensen
}

Injection of chemically tuned, 'smart' water in oil reservoirs may increase both oil recovery rates and the total recovery (e.g. Morrow \& Buckley 2011; Austad 2013; Zeinijahromi et al. 2015). This kind of water management has gained increased importance in the Danish North Sea reservoirs due to decreasing sweep efficiency in maturing oilfields. Knowledge about the compatibility of the injected water with local formation waters is, however, a prerequisite for successful implementation. Here, we present a regional overview of formation waters from oil reservoirs in the Danish North Sea, which comprise three main types of formation brine, and one type of modified seawater related to extensive water flooding. The water types show a distinct geographical distribution, which reflects original connate waters that are modified by saline brine being either depleted or enriched in $\mathrm{SO}_{4}{ }^{2-}$.

\section{Formation water and produced water database}

In order to characterise the water types we have selected a total of 33 water analyses, 25 of produced water and six of formation water from North Sea wells (three core samples from the Francisca-1 well and production tests from the Boje-1, Elna-1 and M-9X, wells) and finally two analyses of seawater (North Sea mean water composition and a treated low-sulphate seawater), see Fig. 1. For characterisation, samples analysed for $\mathrm{Na}, \mathrm{K}, \mathrm{Ca}^{2}, \mathrm{Mg}^{2}, \mathrm{Sr}^{2}, \mathrm{Ba}^{2}, \mathrm{Cl}^{-}$, and $\mathrm{SO}_{4}^{2-}$ were used. Water density had been measured for most of the samples, however, it was estimated for four samples. The data were collected from Samuelsen et al. (2009), Mackay et al. (2012), and Undall-Behrend (2012) and from final well reports for the Boje-1, Elna-1, Francisca-1 and M-9X wells.

\section{Water type classification}

To classify the water types in our database, Principal Component Analysis (PCA) was applied, whereby a matrix $X$ of measured data ( $N$ samples, $P$ variables) is transformed into sets of projection subspaces delineated by Principal
Components (each a linear combination of all $P$ variables), which display variance-maximised interrelationships between variables (Esbensen 2010, Esbensen et al. 2015). PCA score plots display groupings, or clusters, of samples based on compositional similarities, as described by the variable correlations (shown in accompanying loading plots). They also quantify the proportion of total dataset variance that can be modelled by each component, see Fig. 2. All data analyses in this work are based on auto-scaled data.

The data analysis was performed in two steps. Step one is a PCA analysis of all 33 samples to investigate relationships between seawater and reservoir water (Fig. 2A, B). Based hereon, pure seawater and the samples produced from Skjold, Dan B, Dan F and Halfdan, which represent extensively seawater-flooded reservoirs, were removed



Fig. 1. Location of the wells used for water-type characterisation in the Danish part of the North Sea. 

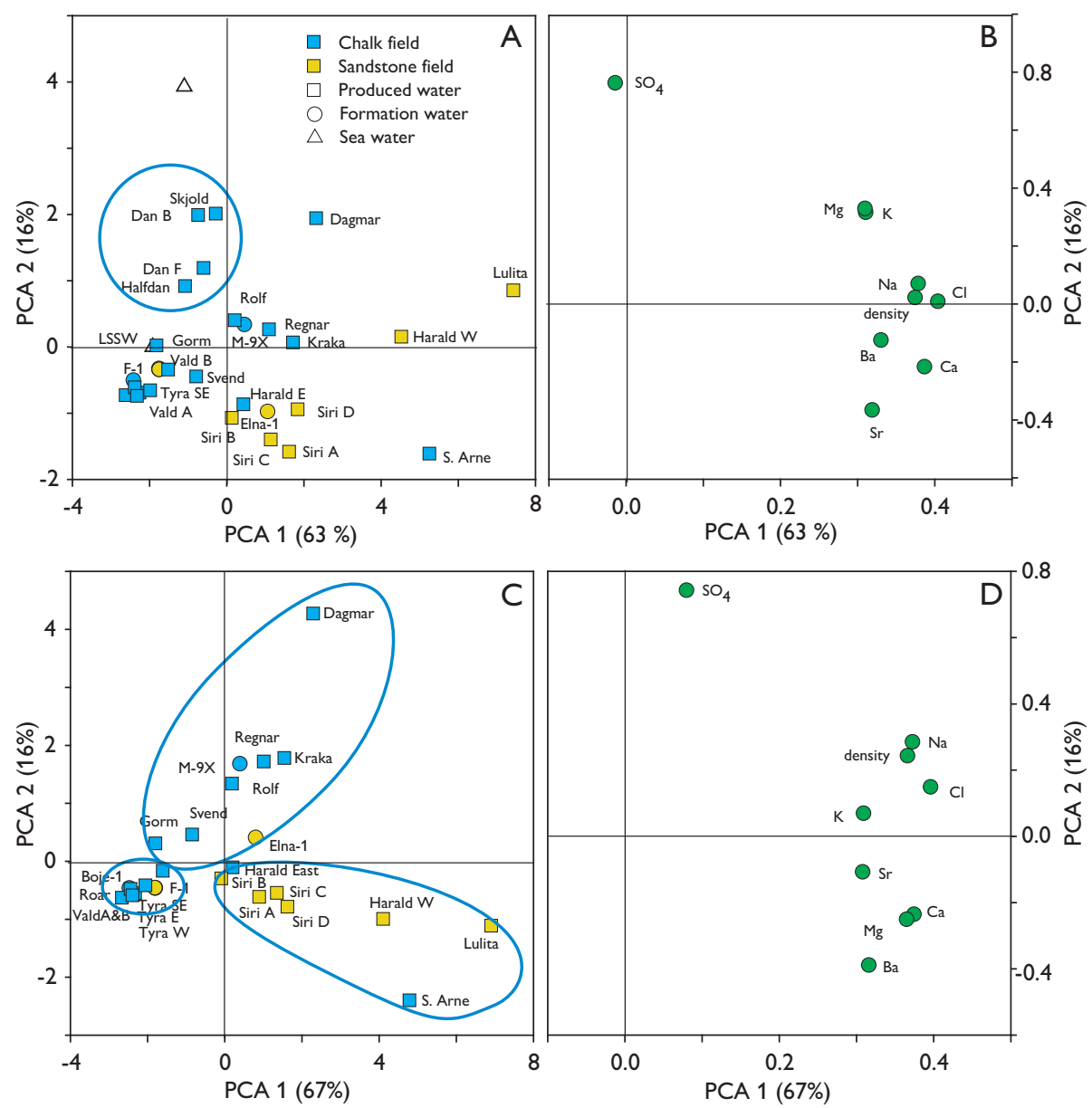

Fig. 2. Principal component analysis, PCA. A: Score. B: loading plot of PCA on all data. C: score. D: loading plot of PCA from which seawater from the Dan B, Dan F, Skjold and Halfdan installations and produced waters were excluded. The plot models $79 \%$ (A, B) and $83 \%(C, D)$ of the total data variance, respectively; variance proportions are shown along each component axis. Water types are classified according to their groupings in A (water type 4) and C (water type 1, 2, 3). F-1: Francisca-1. Vald: Valdemar. SW: seawater. LSSW: low $\mathrm{SO}_{4}^{2-}$-treated seawater. to examine the relationships between the primary water types, which is done in step 2 of the analysis (Fig. 2C, D). In both PCA models the first two principal component axes resolve $80 \%$ of the total data variance, with the main trend expressed on the PCA-1 axis being salinity variation (seen as high positive PCA-1 loadings for $\mathrm{Cl}, \mathrm{Na}$ and $\mathrm{K}$ ). The PCA-2 axis displays high positive loadings of $\mathrm{SO}_{4}^{2-}$ and high negative loadings of elements such as $\mathrm{Ba}, \mathrm{Sr}, \mathrm{Mg}$ and $\mathrm{Ca}$.This could indicate that $\mathrm{SO}_{4}^{2-}$ concentrations control the concentration of $\mathrm{Ba}^{2+}, \mathrm{Sr}^{2+}, \mathrm{Mg}^{2+}$ and $\mathrm{Ca}^{2+}$ due to the low solubility of e.g. barite $\left(\mathrm{BaSO}_{4}\right)$ and anhydrite $\left(\mathrm{CaSO}_{4}\right)$. However, chemical speciation calculations using the numerical code PHREEQC suggest sub-saturation of $\mathrm{SO}_{4}^{2-}$-bearing minerals except for barite in all water types.

\section{Composition and occurrence of water types}

From the PCA analysis, four water types can be identified based on natural groupings in the PCA-2 versus PCA-1 plot (Fig. 2). The most likely cause of the salinity varia- tion is a variable mixing of primary connate waters with brine originating from Permian Zechstein salt, which may or may not be $\mathrm{SO}_{4}{ }^{2-}$-rich (Warren et al. 1994). The characteristics and occurrence of each of the water types are presented below. Water types 1-3 have compositional characteristics similar to types presented in the comprehensive overview paper by Warren et al. (1994).

Water type 1 plots within a very narrow group in the third quadrant of the PCA-2- PCA-1 plot (Fig. 2C), characterised by low salinity water with an overall low abundance of all elements (Fig. 3). This water type is found in the Boje1, Francisca-1, Roar, Tyra E, Tyra SE and Valdemar fields and thus occurs in a broad range of reservoirs from Lower to Upper Cretaceous - Paleocene chalk to Oligocene sandstone. The location borders the greater Tyra-Valdemar area, in geographical areas separated from saline Permian brines (Fig. 4). The water is interpreted to reflect unmodified $\mathrm{SO}_{4}{ }^{2-}$-depleted formation water. 
Fig. 3. A: Water concentration normalised to seawater composition. B: Calculated average compositions of the four water types observed in this study. For display purposes, $\mathrm{Ba}^{2+}$ and $\mathrm{Sr}^{2+}$ concentrations of $0 \mathrm{ppm}$ in seawater have been increased to $1 \mathrm{ppm}$.

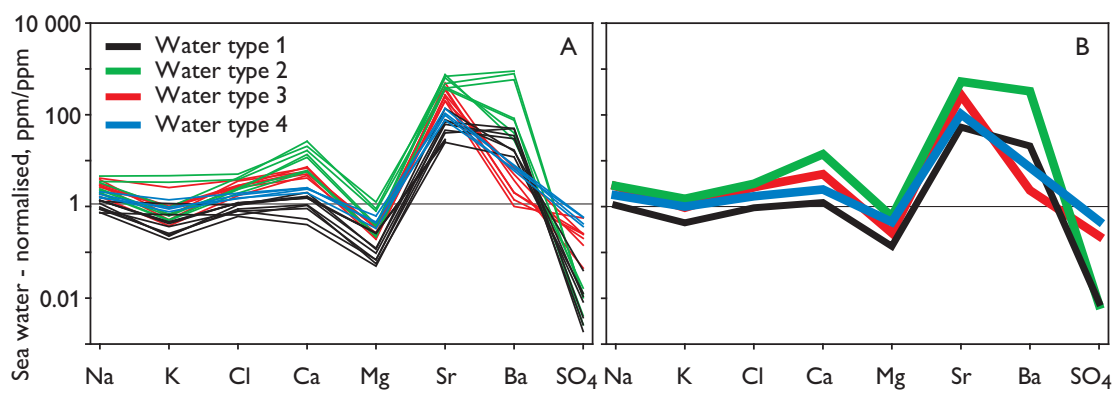

Water type 2 is characterised by positive PCA-1 and negative PCA-2 scores (Fig. 2C) and can compositionally be characterised by medium to high salinities, no $\mathrm{SO}_{4}{ }_{4}^{2-}$, and high to very high $\mathrm{Ca}$ and $\mathrm{Ba}$ concentrations (Fig. 3). This water type occurs in the Harald E and W, Lulita, S. Arne, Siri, Nini, Stine and Cecilie fields, all of which are located in the northern part of the Danish North Sea and in the Siri Canyon - i.e. in reservoirs that range in age from Jurassic to Paleocene and both in chalk and sand lithologies. Water type 2 is interpreted to reflect formation water modified by $\mathrm{SO}_{4}^{2-}$ depletion.

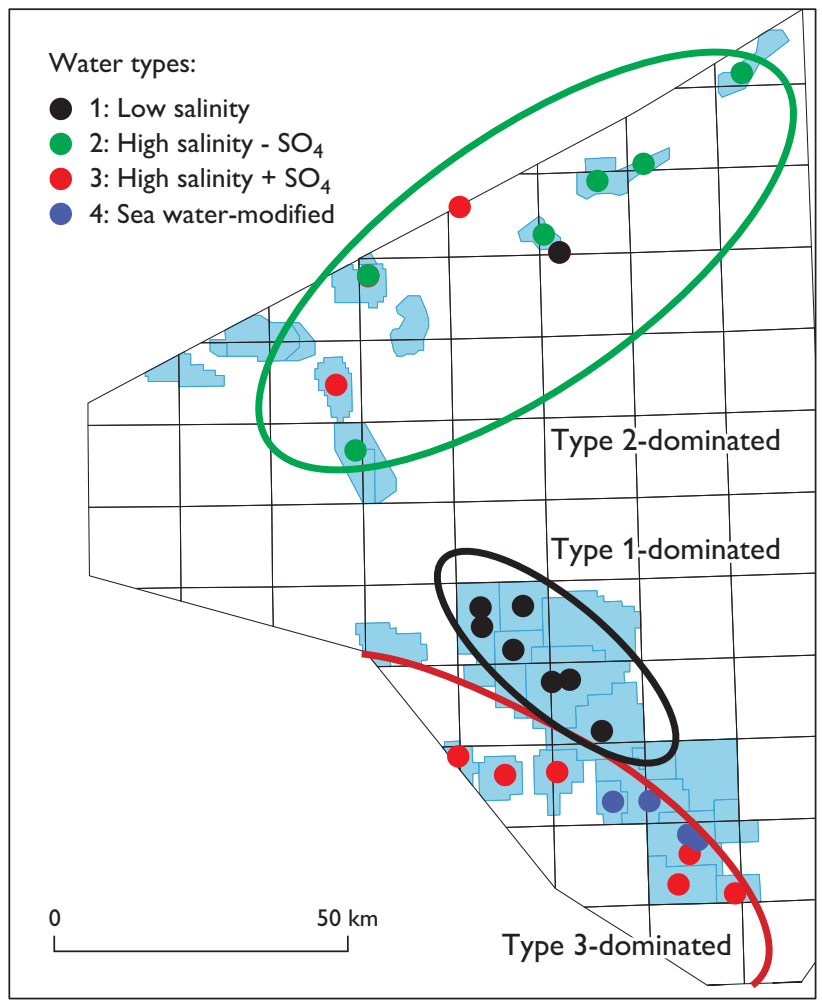

Fig. 4. Occurrence of resolved water types in the Danish oil- and gasfields. For location names see Fig. 1. The water types are geographically restricted and reflect both structural basin development and reservoir conditions. The seawater modified water type 4 is assumed to have originated as water type 3 based on pre-waterflooding formation water analysis and its structural position within the salt dome province.
Water type 3 plots with generally positive PCA-1 and PCA-2 scores in Fig. 2C, reflecting medium to high salinities and variable, low to high $\mathrm{SO}_{4}^{2-}$ concentrations (Fig. 3). This water type is found in the Dagmar, Elna-1, Gorm, Kraka, M-9X, Regnar, Rolf and Svend fields, most clearly expressed in the intensely fractured Dagmar field sample. This field is situated on top of a salt dome that has reservoir oil in chalk and Zechstein carbonates. Type 3 waters are restricted to chalk reservoirs overlying salt domes in the southern salt dome province, and are interpreted as formation water enriched in $\mathrm{SO}_{4}{ }^{2-}$.

Water type 4 plots close to, or together with seawater with negative PCA-1 and positive PCA-2 scores in Fig. 2A, corresponding to low to medium salinity with high $\mathrm{SO}_{4}^{2-}$ concentrations (Fig. 3). This water type occurs in the Dan, Halfdan and Skjold fields and is interpreted to be the result of decades of extensive water flooding performed by the operator (Energistyrelsen 2013). Analyses of water from the Dan field (the M-9X well; Fig. 2C) prior to flooding suggest that it was originally filled with water type 3 .

\section{Implications for enhanced oil recovery by injection of 'smart' water}

Water injection is currently applied in several of the Danish oil fields, mainly in order to provide pressure support. However, such injection may also have secondary effects such as increased imbibition, alteration of the reservoir rock wettability or mobilisation of fines with a resulting increase in reservoir sweep. In some cases, the specific chemical composition of the injection water may be important. Thus, it has been suggested that carbonate rocks become more water wet if the injection water contains $\mathrm{SO}_{4}^{2-}$ in combination with excess $\mathrm{Ca}^{2+}$ or $\mathrm{Mg}^{2+}$ (e.g. Austad 2013). The result is enhanced oil recovery, which is even more pronounced both for chalk and sandstone if the salinity of the injection water is significantly lower than that of the formation water (Morrow \& Buckley 2011; Austad 2013). 
Although several different mechanistic explanations have been suggested, a supposed change in carbonate rock wettability would involve surface chemical reactions such as ion exchange between $\mathrm{SO}_{4}{ }^{2-}$ and oil molecules (e.g. Austad 2013). Following this argumentation, it is likely that injection of 'smart' $\mathrm{SO}_{4}{ }^{2-}$-bearing water in chalk reservoirs would have the largest effect in reservoirs with saline formation water depleted in $\mathrm{SO}_{4}^{2-}$ (water type 2). However, the application of $\mathrm{SO}_{4}{ }^{2-}$-rich water in reservoirs with this type of connate water is not straightforward, as there is a risk of scaling and subsequent clogging of the reservoir if the injected water is mixed with the connate water, due to its high concentrations of $\mathrm{Ca}^{2+}, \mathrm{Ba}^{2+}$, and $\mathrm{Sr}^{2+}$ (Samuelson et al. 2009; Mackay et al. 2012). Another risk related to injection of $\mathrm{SO}_{4}^{2-}$-bearing water in $\mathrm{SO}_{4}^{2-}$-depleted reservoirs is the possibility of hydrogen sulphide formation due to $\mathrm{SO}_{4}^{2-}$ reducing microbial activity.

For reservoirs already enriched in $\mathrm{SO}_{4}^{2-}$ (water type 3) or with water of relatively low salinity (water type 1), other types of injection water may have greater effects on oil recovery.

In shaly sand reservoirs, injection of low-salinity 'smart' water can also mobilise clay fines, in order to intentionally clog current flow paths and redirect the flow in the reservoir (e.g. Morrow \& Buckley 2011; Zeinijahromi et al. 2015). In this case, the mobilisation of non-swelling clays is provoked solely by the change in salinity. Therefore, application of this type of water technology seems to be most relevant in reservoirs with connate water of relatively high salinity, such as most of the reservoirs in the Siri Canyon (water type 2).

\section{Conclusions}

Four water types are present in the Danish North sea: $\mathrm{SO}_{4}^{2-}$-bearing, medium- to highly saline water (type 3), $\mathrm{SO}_{4}^{2-}$-depleted medium to high saline water (type 2), $\mathrm{SO}_{4}{ }^{2-}$ -depleted low saline (type 1), and a seawater-modified manifestation (type 4 water). These water types reflect variable mixing of connate water with deeper brines and are tied in with the known hydrocarbon provinces. Type 2 represents the Siri Canyon and the South Arne - Svend areas. Water type 3 is characteristic of salt dome reservoirs, while water type 1 represents the greater Tyra-Valdemar area. The variable chemistry of the formation water in the Danish North Sea imposes regional differences in production strategies and hence in the designing of 'smart' water for enhanced oil recovery. The classification of water types presented here shows that their composition is predictable and related to geographical domains in the North Sea. This may be useful when designing procedures for optimal water management in the Danish North Sea, e.g. application of low salinity water flooding on mature fields, or in some cases even during the exploration stage.

\section{References}

Austad, T. 2013: Water-based EOR in carbonates and sandstones: New chemical understanding of the EOR potential using 'smartwater'. In: Sheng, J.J. (ed.): Enchanced oil recovery field case studies, 301-335. Waltham, MA, USA: Elsevier.

Energistyrelsen, 2013: Danmarks olie- og gasproduktion 2013, 105 pp. København: Energistyrelsen.

Esbensen, K.H. 2010: Multivariate data analysis - in practice. An introduction to multivariate data analysis and experimental design, 5th edition, 598 pp. Oslo: CAMO Software AS.

Esbensen, K., Schovsbo, N.H. \& Kristiansen, L. 2015: Down-hole permeability prediction - a chemometric wire-line log feasibility study from a North Sea chalk well. Geological Survey of Denmark and Greenland Bulletin 33, 13-16.

Mackay, E., Ginty, W.R. \& Jones, T.J. 2012: Oilfield scale management in the Siri asset - paradigm shift due to the use of mixed PWRI / seawater injection. 74th EAGE Conference and Exhibition incorporating EUROPEC 2012. Copenhagen, Denmark, 4-7 June 2012. SPE 154534, 1-12.

Morrow, N. \& Buckley, J. 2011: Improved oil recovery by low-salinity waterflooding. Journal of Petroleum Technology 63, 106-112.

Samuelsen, E.H., Frederiksen, R.A., Heath, S.M., Thornton, A., Sim, M., Arefjord, A. \& McAra, E.K. 2009: Downhole scale control through continuous injection of scale inhibitor in the water injection - a field case. Conference Tekna Geilo paper 240309, 23 pp.

Undall-Behrend, G. 2012: Produceret vand på Tyra Øst F. Bachelorprojekt Århus Maskinmesterskole, 75 pp.

Warren, E.A., Smalley, C.P. \& Howarth, R.J. 1994: Compositional variations of North Sea formation waters, Part 4. Geological Society, London. Memoirs 15, 119-208.

Zeinijahromi, A., Ahmetgareev, V., Badalyan, A., Khisamov, R. \& Bedrikovetsky, P. 2015: Case study of low salinity water injection in Zichebashskoe field. Journal of Petroleum Science Research 4, 16-31. 